\title{
NON-TRAUMATIC ACQUIRED TETRAPLEGIA: CASE REPORT
}

\author{
G. M. Pool \\ Zuiderziekenhuis, Rotterdam (Holland)
}

\begin{abstract}
A patient who gradually developed tetraplegia caused by an intra-medullary tumour is described. Over a period of 13 years the patient and her family coped very well with the handicap. After neurosurgical intervention no neurological recovery was achieved, but her head movements were restored. This made mobility with an electrical chin-steered wheelchair possible. Some of the differences between an acute and a gradually acquired tetraplegia are discussed.
\end{abstract}

Key Words: Tetraplegia; Intra-medullary tumour; Patient reactions; Disability; Acceptance.

\section{Introduction}

ACCEPTANCE of disability and patient reactions after a medical disaster are seldom discussed, although they are observed daily in medical practice. Kerr and Thompson (I972) discussed the problem of acceptance of disability of sudden onset in paraplegia, and concluded that the major factors for good mental adjustment are the patient's previous mental and family background, his age, and also that it takes at least two years for the average patient to stabilise.

It is probable that acceptance and patient reactions differ in patients who acquire their handicap suddenly or gradually. The most severe handicapped are those with a high-level tetraplegia. If a traumatic high-level tetraplegic patient ( $\mathrm{C}_{4}$ and above) survives, according to Burnham and Werner (1978) such a patient invariably states: 'Now that I don't have the use of my arms and legs, life is meaningless and I want to die'. Burnham and Werner gave a list of several points upon which the high level tetraplegic is dependent: the most important being transport, communication, feeding, and A.D.L. (self help). Cheshire and Flack (I978) remarked in a paper on respiratory rehabilitation of the tetraplegic that such a patient has had an overwhelming physical and psychological injury and that the future appears to have nothing but gloom and dependence to offer. To break through this barrier of defeat, the patient often has an urgent need for something which will give him an early obvious visible or tangible success.

One of the problems in the rehabilitation of the tetraplegic patient is that, particularly with high lesions, it is difficult to provide immediately obvious useful practical benefits.

\section{Case Report}

\section{A.H.S. born 1946}

The patient began complaining of headache, vomiting and attacks of severe pain in the neck region in 1963. No definite diagnosis was reached although the complaints were so severe that she had to leave school.

After about a year the symptoms were less marked and she managed to pass her last school examination. She did however complain of a tingling sensation in both hands, and the left one became paretic. In 1969 she decided to take up lessons in the English 
language to assist her to obtain employment, as she could not get a job because of her handicaps.

In the meantime a diagnosis of toxoplasmosis was reached, and the symptoms and signs were considered to be due to that disease. In I 978 walking became very difficult and unsafe for her, and it was therefore decided that she should be trained to use an electric wheelchair. At that time she was only able to use her right hand slightly. The family moved to an adapted home, and at the same time the patient was admitted to hospital for observation. Myelography, and a high level of albumin in the spinal fluid suggested the possibility of a cord malformation in the cervical region.

Because of her stiff neck and useless hands, she required more help than her parents were able to give her. Nevertheless she did not desire an exploratory spinal operation, as she was afraid to lose her voice, her only method of communication. Only when she was reassured on this point did she give permission.

A laminectomy from $\mathrm{C}_{2}$ to $\mathrm{C}_{7}$ was performed, and the spinal cord was found to be swollen and to have an abnormal vascular pattern. A diagnosis of an intra-medullary tumour was established. The tumour was left in place. There were no complications following this operation.

No return of hand movements whatsoever was observed, but an unforeseen return of active neck movements made manoeuvring a chin-steered electric wheelchair possible (Fig. I). After the operation, as a well-adapted tetraplegic she took advantage of all the electronic devices. Considerable improvement was achieved by the operation in her communication problems, and there was no voice disturbance. Although she appeared to have sufficient care from her parents, and in a way a purposeful life, it also became clear that two years after the operation and 17 years after the onset of her symptoms she had really become fully aware of her situation. Now electronic devices alone are no longer sufficient to meet her communication problems. She wants more independenceincluding independence from her parents, and to be able to travel independently like everyone else because 'what will happen next year to me?'

According to Burnham and Werner (I978) rehabilitation could be defined as maximising all of the patient's abilities and assisting the patient to develop her or his mind and ability to communicate. Realisation of this aim is to a large extent dependent upon the way the patient acquired the handicap, whether suddenly or gradually. Acceptance of disability and patient reactions are difficult to predict. In patients with high-level tetraplegia the reactions are also influenced by the fact that such patients have no real choice but to survive and to accept their fate. This is important both those who acquired their handicap suddenly and those who develop it gradually.

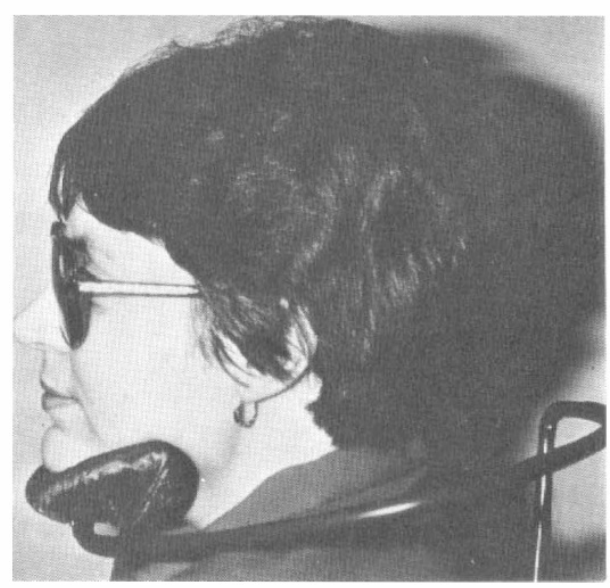

FIG. I

Patient's neck supported with a special chin-neck appliance. 


\section{RÉSUMÉ}

Description d'un cas de tetraplegie, lentement devellopé et do son origine, un tumor intramedullair cervical. L'adaptation à l'handicap et les reactions de la malade tetraplegique et de ses parents sont dêcrites. Probablement il y a un différence entre la reaction du tetraplegique acute et du patient qui a devellopé son maladie lentement.

\section{ZUSAMMENFASSUNG}

Beschrieben wird ein Fall einer Tetraplegie, die langsam hervor trat un ihre Ursache: eine intramedulare Tumor in die cervicale region. Die Adaptation der Patientin und ihrer Familie werden aus einander gesetst. Wahrscheinlich gibt es ein Unterschied zwischen die Reactionen der Patienten einer acute und die einer sich langsam entwicklende Tetraplegie.

\section{REFERENCES}

Burnham, L. \& Werner, G. (1978). The high level tetraplegic: Psychological survival and adjustment. Paraplegia, 16, I84-192.

Cheshire, D. J. E. \& FlaCK, W. J. (I978). The use of operant conditioning techniques in the respiratory rehabilitation of the tetraplegic. Paraplegia, 16, I62-175.

KERR, W. G. \& Thompson, M. A. (1972). Acceptance of disability of sudden onset in Paraplegia. Paraplegia, 10, 94-102. 